VERSATI LE SYNTHESI S OF

5, 6- DI HYDRO 1, 4- DI TH EPI NS AND THEI R SYNTHETI C APPLI CATI ONS

\begin{tabular}{|l|l|}
\hline 著者 & $\begin{array}{l}\text { Sai go Kazuhi ko, Hashi mot o Yuki hi ko, Fang Lan, } \\
\text { Hasegawa Nasaki }\end{array}$ \\
\hline $\begin{array}{l}\text { j our nal or } \\
\text { publ i cat i on ti tl e }\end{array}$ & Het er Ocycl es \\
\hline vol une & 29 \\
\hline number & 11 \\
\hline page range & $2079-2082$ \\
\hline year & $1905-06-11$ \\
\hline URL & ht t p: //hdl . handl e. net /10173/964 \\
\hline
\end{tabular}




\title{
VERSATILE SYNTHESIS OF 5,6-DIHYDRO-1,4-DITHIEPINS AND THEIR SYNTHETIC APPLICATIONS
}

\author{
Kazuhiko Saigo, * Yukihiko Hashimoto, Lan Fang, and Masaki Hasegawa \\ Department of Synthetic Chemistry, Faculty of Engineering, \\ The University of Tokyo, Hongo, Bunkyo-ku, Tokyo 113, Japan
}

\begin{abstract}
Readily available acyloin trimethylene dithioacetals rearranged in the presence of trimethylsilyl trifluoromethanesulfonate to give 5,6-dihydro-1,4-dithiepins.

These compounds were converted to olefinic or acetylenic compounds using low valent metallic reductants.
\end{abstract}

In the course of our research on cationic species chemistry, 1 acyloin trimethylene dithioacetals 1 were found to give 5,6-dihydro-1,4-dithiepins 2 in an acidic medium via alkylthio migraion. For the synthesis of 1,2bis(alkylthio)alkenes, including 5,6-dihydro-1,4-dithiepins, only a few synthetic methods were reported. The nucleophilic substitution reaction of thiolate anion to vinylene dihalides is considered to be a convenient method for the preparation of unsubstituted 1,2-bis(alkylthio)ethylenes. ${ }^{2}$ Several oxidative ring expansions of cyclic dithioacetals ${ }^{3}$ and other methods ${ }^{4}$ were also successfully applied for the synthesis of 5,6-dihydro-1,4-dithiins and related compounds. However, generalities for all of these reactions are not clear, and the synthesis of unsymmetrically substituted 5,6-dihydro-1,4-dithiepins may be difficult by using these methods. Recently, Warren et al. reported alkylthio migration reaction of acyloin diphenyl dithioacetals. ${ }^{5}$ Although 1,2-bis(alkylthio)alkene type compound was formed in some special cases, another type of compound was usually produced as a main product in the system. In this communication, we wish to report a convenient method for the synthesis of 5,6-dihydro-1,4-dithiepins and their synthetic applications.

Acyloin trimethylene dithioacetals 1 are easily prepared from 2 -substituted 1,3-dithianes and aldehydes. ${ }^{6}$ When the diphenyl derivative $1 \mathrm{a}\left(\mathrm{R}^{1}=\mathrm{R}^{2}=\mathrm{Ph}\right)$ was treated with tin(IV) chloride in dichloromethane at $-23^{\circ} \mathrm{C}$ for $10 \mathrm{~h}$, the ring expanded product $2 \mathrm{a}\left(\mathrm{R}^{1}=\mathrm{R}^{2}=\mathrm{Ph}\right)$ was obtained in $26 \%$ yield through elimination of hydroxyl group and subsequent rearrangement of alkylthio group. The optimized conditions were examined for bisphenethyl derivative $1 \mathrm{~b}$ $\left(\mathrm{R}^{1}=\mathrm{R}^{2}=\mathrm{PhCH}_{2} \mathrm{CH}_{2}\right)$. In this case, the double bond isomer $3 \mathrm{~b}\left(\mathrm{R}^{1}=\mathrm{PhCH}_{2} \mathrm{CH}_{2}, \mathrm{R}^{3}=\mathrm{PhCH}_{2}, \mathrm{R}^{4}=\mathrm{H}\right)$ was also produced, which was the initial product of this reaction. Thus, when $R^{2}$ group has $\alpha$-hydrogen(s), desired 5,6dihydro-1,4-dithiepin was formed from 3 by double bond isomerization under thermodynamic control. After screening of Lewis acids, solvents, etc., the highest yield and selectivity were achieved when the reaction was carried out using trimethylsilyl trifluoromethanesulfonate in ether at room temperature for $24 \mathrm{~h}$. Furthermore, addition of molecular 
sieve $5 \mathrm{~A}$ as a dehydrating agent was found to improve the yields. Weak basic molecular sieve $4 \mathrm{~A}$ was not effective since it inhibited the above mentioned acidic double bond isomerization from 3 to 5,6-dihydro-1,4-dithiepin 2, resulting in low selectivities.
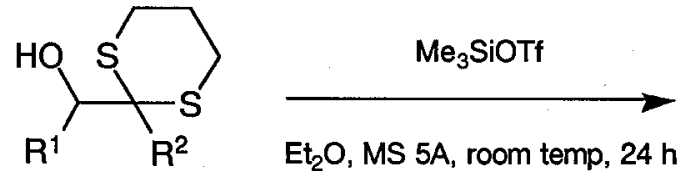

1

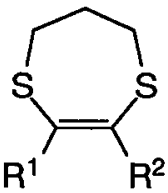

2

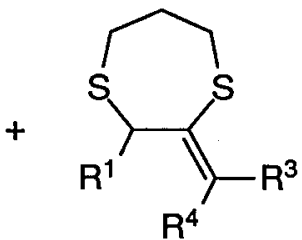

3

The results for the synthesis of 5,6-dihydro-1,4-dithiepins from various substrates under the optimized conditions are summarized in Table 1. As can be seen in Table 1, 5,6-dihydro-1,4-dithiepins were generally synthesized in moderate to high yields. In addition, the reaction proceeded smoothly including substrates having electron withdrawing group (entry 3 ) or no substituent (entry 7).

Table 1. Synthesis of 5,6-Dihydro-1,4-dithiepins ${ }^{a}$

\begin{tabular}{ccccc}
\hline Entry & $\mathrm{R}^{1}$ & $\mathrm{R}^{2}$ & Yield (\%) & $2: 3$ \\
\hline 1 & $\mathrm{Ph}$ & $\mathrm{Ph}$ & 83 & $-\mathrm{b}$ \\
2 & $\mathrm{Ph}$ & $\mathrm{PhCH}_{2} \mathrm{CH}_{2}$ & 88 & $100: 0$ \\
3 & $\mathrm{Ph}$ & $\mathrm{COOEt}$ & $56 \mathrm{c}$ & $-\mathrm{b}$ \\
4 & $\mathrm{PhCH}_{2} \mathrm{CH}_{2}$ & $\mathrm{PhCH}_{2} \mathrm{CH}_{2}$ & 83 & $75: 25$ \\
5 & $\mathrm{PhCH}_{2} \mathrm{CH}_{2}$ & $\mathrm{Me}_{2} \mathrm{CH}$ & 80 & $37: 63$ \\
6 & $\mathrm{PhCH}_{2} \mathrm{CH}_{2}$ & $\mathrm{Me}$ & 61 & $100: 0$ \\
7 & $\mathrm{PhCH}_{2} \mathrm{CH}_{2}$ & $\mathrm{H}$ & 31 & $-\mathrm{b}$ \\
\hline
\end{tabular}

a) All new compounds gave satisfactory spectroscopic data.

b) There is no possibility to form 3 .

c) Reaction was carried out at $0{ }^{\circ} \mathrm{C} \rightarrow$ room temperature. 
The general procedure is as follows: To a stirred suspension of acyloin trimethylene dithioacetal $1(0.30 \mathrm{mmol})$ and molecular sieves $5 \mathrm{~A}$ in ether $(3 \mathrm{ml})$ was added an ethereal solution of trimethylsilyl trifluoromethanesulfonate ( $2 \mathrm{ml}$, $0.36 \mathrm{mmol}$ ) at room temperature. The reaction was continued for $24 \mathrm{~h}$ and quenched by addition of saturated aqueous sodium hydrogencarbonate. The resulting mixture was filtered through a Celite pad and extracted with ethyl acetate (3 $\times 10 \mathrm{ml}$ ). The combined extracts were dried and concentrated under reduced pressure. Purification with thin layer chromatography gave 5,6-dihydro-1,4-dithiepin 2.

Because 5,6-dihydro-1,4-dithiepins have a unique structure, in the next stage, we investigated the synthetic applications of the product obtained. As a result, it was found that stilbene (4, predominantly cis -isomer) could be synthesized by treating diphenyl derivative $2 \mathrm{a}$ with low valent titanium reagent ${ }^{7}$ generated from titanium(IV) chloride and lithium aluminum hydride. It has been recently reported that similar desulfurization reaction can be carried out with Raney nickel for an extremely particular case; a steroidal 5,6-dihydro-1,4-dithiin. ${ }^{8}$

Hydrogen peroxide oxidation of $2 \mathrm{a}$ under usual conditions afforded bissulfone 5 in high yield, which was reduced with lithium dimethylcuprate to give diphenylacetylene (6) in $83 \%$ yield.

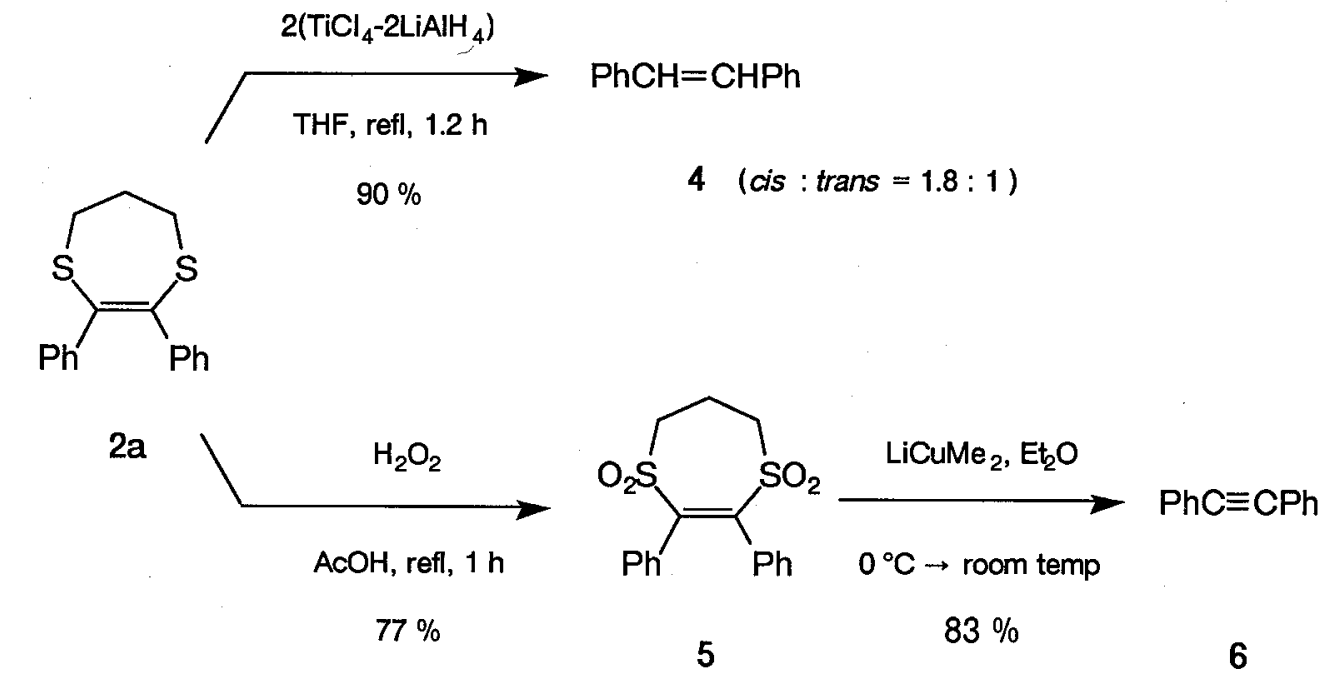

Thus it was found that 5,6-dihydro-1,4-dithiepins, including unsymmetrically substituted ones, were conveniently synthesized from readily available compounds and were also valuable synthetic blocks for olefin and acetylene synthesis. Particularly, no vicinal reductive elimination reaction with a cuprate reagent has been reported so far, ${ }^{9}$ further study is now under investigation in our laboratory. 


\section{REFERENCES}

1. Y. Hashimoto, S. Machida, K. Saigo, J. Inoue, and M. Hasegawa, Chem. Lett, 1989, 943.

2. W. E. Truce, M. M. Boudakian, R. F. Heine, and R. J. McManimie, J. Am. Chem. Soc., 1956, 78, 2743; M. Tiecco, L. Testaferri, M. Tingoli, D. Chianelli, and M. Montanucci, J. Org. Chem., 1983, 48, 4795.

3. H. Yoshino, Y. Kawazoe, and T. Taguchi, Synthesis, 1974, 713; C. H. Chen, Tetrahedron Lett., 1976, 25; C. H. Chen and B. A. Donatelli, J. Org. Chem., 1976, 41, 3053; J. W. A. M. Janssen and H. Kwart, ibid., 1977, 42, 1530; N. Ueda, H. Shimizu, T. Kataoka, and M. Hori, Tetrahedron Lett., 1984, 25, 757; C. G. Francisco, R. Freire, R. Hemández, J. A. Salazar, and E. Suárez, ibid., 1984, 25, 1621.

4. T. Cohen, D. Ouellette, and W. M. Daniewski, Tetrahedron Lett., 1978, 5063; T. Cohen, D. Ouellette, K. Pushpananda, A. Senaratne, and L.-C. Yu, ibid., 1981, 22, 3377; G. Adiwidjaja, L. Kistenbrügger, and J. Voss, $J$. Chem. Res., 1981, (S) 88, (M) 1227; T. Cohen, R. H. Ritter, and D. Ouellette, J. Am. Chem. Soc, 1982, 104, 7142; J. Voss, C. von Bülow, T. Drews, and P. Mischke, Acta Chem. Scand., 1983, B37, 519.

5. P. Blatcher, J. I. Grayson, and S. Warren, J. Chem. Soc, Chem. Commun., 1976, 547; P. Blatcher and S. Warren, ibid., 1976, 1055; idem, J. Chem. Soc., Perkin Trans 1, 1979, 1074; idem, ibid, 1985, 1055. See also, S. Warren, Acc. Chem. Res., 1978, 11, 401. For the alkylthio migration reactions in the related systems, see: J. A. Marshall and H. Roebke, J. Org. Chem., 1969, 34, 4188; A. de Groot and B. J. M. Jansen, Tetrahedron Lett., 1981, 22, 887; idem, Symthesis , 1985, 434; T. Sato, H. Okazaki, J. Otera, and H. Nozaki, J. Am. Chem. Soc., 1988, 110, 5209; T. Sato, M. Inoue, S. Kobara, J. Otera, and H. Nozaki, Tetrahedron Lett., 1989, $30,91$.

6. B.-T. Gröbel and D. Seebach, Synthesis, 1977, 357. See also S. Takano and K. Ogasawara, J. Synth. Org. Chem. Jpn., 1977, 35, 795.

7. T. Mukaiyama, M. Hayashi, and K. Narasaka, Chem. Lett., 1973, 291; T. Mukaiyama, M. Shiono, K. Watanabe, and M. Onaka, ibid., 1975, 711; Y. Watanabe, M. Shiono, and T. Mukaiyama, ibid., 1975, 871; T. Mukaiyama, K. Saigo, and O. Takazawa, ibid, 1976, 1033; A. Ishida and T. Mukaiyama, ibid., 1976, 1127.

8. J. R. Williams and P. B. Tran, Synthesis, 1988, 705.

9. For the reductions with organocuprates, see: C. Sahlberg and A. Claesson, J. Org. Chem., 1984, 49, 4120; T. Ishihara, T. Maekawa, Y. Yamasaki, and T. Ando, ibid., 1987, 52, 300; S. Takano, Y. Sekiguchi, and K. Ogasawara, J. Chem. Soc., Chem. Commun., 1988, 449 and references cited therein. 